\title{
A formaçáo inicial em cursos de licenciatura: o caso dos alunos estagiários da UFSM
}

\author{
Sandra Agostini* \\ Eduardo Adolfo Terrazzan**
}

\section{Resumo}

Este artigo originou-se de uma investigação acerca da organização e desenvolvimento de Estágios Curriculares em Cursos de Licenciatura da Universidade Federal de Santa Maria (UFSM). Neste estudo, tomamos por base os 13 Cursos de Licenciatura em Letras/Português, em Letras/Inglês, em Letras/Espanhol, em Educação Física, em Química, em Física, em Ciências Biológicas, em Música, em Matemática, em Filosofia, em Geografia, em Artes Visuais e em História, enfatizando o olhar dos alunos estagiários. Como fonte de informaçôes, utilizamos questionários de perguntas abertas e grupos de discussão. Constatamos que os estagiários, em sua maioria, tiveram um bom relacionamento com seus professores orientadores de estágio; boa parte $(58,44 \%)$ recebeu orientação para conseguir vaga de estágio nas escolas; foram bem recebidos pelas escolas; os professores regentes de turma pouco contribuem para a realização do estágio; a escola quase não os acompanha; a maioria (97\%) dos estagiários considerou sua formaçáo inicial como um momento importante de aprendizagem.

Palavras-chave: cursos de licenciatura, estágio curricular, alunos estagiários, formação inicial de professores, escola.

Initial formation in licentiate degree courses: the case of UFSM student-teachers

\section{Abstract}

This article arose out of an analysis of the organization and carrying out of teaching practice modules in licentiate courses at the Federal University of Santa Maria (UFSM). In this study, the thirteen Licentiate Courses in Letters/Portuguese, Letters/English, Letters/ Spanish, Physical Education, Chemistry, Physics, Biological Sciences, Music, Mathema-

* Professora da Rede Municipal de Ensino do Município de Chapecó/SC. E-mail: sandraagostini04@ yahoo.com.br.

* Professor associado do Centro de Educação da Universidade Federal de Santa Maria (UFSM), do Núcleo de Educação em Ciências e Programa de Pós-Graduação em Educação, do município de Santa Maria-RS, e bolsista do PQ/CNPq. E-mail: eduterrabr@yahoo.com.br. 
tics, Philosophy Geography, the Visual Arts and History are seen through the eyes of student-teachers. As a source of information, open-ended questionnaires and discussion groups were used. It was seen that the majority of student-teachers had a good relationship with their placement supervisors; a large part $(58.44 \%)$ was informed about how to get a placement in a school and were well received by the schools; class teachers gave very little support during placement; the school provides very little monitoring; the majority (97\%) of student-teachers considered their initial formation an important phase in their learning journey.

Keywords: licentiate courses, placement, student-teachers, initial teacher formation, school.

\section{Consideraçóes iniciais}

Este artigo é um recorte proveniente de uma investigação maior acerca do processo de organização e desenvolvimento de Estágios Curriculares em Cursos de Licenciatura da UFSM (Agostini, 2008), que teve como objetivo buscar sugestôes e contribuir para a elaboração de subsídios e parâmetros para as formas de organização e desenvolvimento dos Estágios Curriculares em Cursos de Licenciatura.

Neste estudo, propusemo-nos a investigar "Como se caracteriza a organização e o desenvolvimento dos Estágios Curriculares em Cursos de Licenciatura da UFSM?”. Para isso, tomamos por base os 13 cursos de Licenciatura, em Física, Química, Ciências Biológicas, Música, Matemática, Filosofia, Geografia, Artes Visuais, Letras/Português, Letras/Inglês, Letras/ Espanhol, Educação Física e História.

Para obter tais informaçôes, utilizamos questionários de perguntas abertas e realizamos grupos de discussão com os alunos estagiários inseridos nesses cursos. Neste estudo, abordamos o relacionamento dos alunos estagiários com seus respectivos professores orientadores de estágio, a forma como foram recebidos pelas escolas, a maneira como a orientaçáa foi feita aos alunos estagiários para conseguirem vaga na escola, a falta de participação do professor regente de turma, a falta de acompanhamento das escolas campo de estágio, as disciplinas que mais contribuíram para a realização dos estágios e também a avaliação sobre a sua formação inicial.

Assim, para melhor compreender as atuais configuraçôes curriculares dos cursos de licenciatura em estudo, consideramos importante retomar alguns aspectos presentes nas normativas legais que estão norteando esse 
processo, bem como as discussóes sobre a formação de professores que essas alteraçôes estão provocando no meio acadêmico.

As modificaçóes nas normativas legais de formação de professores para todos os níveis da educação básica, no que se refere ao Estágio Curricular, foram resultados da Lei de Diretrizes e Bases da Educação Nacional (LDBEN), Lei n. 9.394, de 20 de dezembro de 1996, e, mais especificamente, das resoluçóes do Conselho Nacional da Educação (CNE/CP), n. 1 e n. 2, de fevereiro de 2002.

Encontramos na LDBEN - Lei n. 9.394/96, os artigos 65 e 82. O primeiro determina que a carga horária para a formação docente é de, no mínimo, 300 (trezentas) horas. E o segundo destina ao sistema de ensino a criação de normas próprias para a realização de estágios.

Logo, as resoluções do Conselho Nacional da Educação (CNE/CP) n. 1 e n. 2, de fevereiro de 2002, regulamentam e complementam o que foi referido na LDBEN - Lei 9.394/96, acerca da realização de Estágios Curriculares em Cursos de Licenciatura.

No que diz respeito à primeira resolução CNE/CP 1/2002, o artigo $7^{\circ}$ determina no seu inciso IV que as Instituiçôes de Ensino Superior (IES) devem trabalhar conjuntamente com as Escolas de Educação Básica (EEB) no desenvolvimento da formação inicial dos futuros profissionais que nela atuarão. Já o artigo 13 propóe articular a teoria e a prática, a fim de superar os tradicionais problemas decorrentes desde a criação dos Cursos de Licenciatura no Brasil, na década de 1930, no qual a prática era processada desvinculada da teoria, gerando os constantes problemas de dicotomia ainda existentes entre teoria e prática na formação de professores.

Considerando a relevância do Estágio Curricular na formação de professores, o artigo 13, em seu parágrafo 3, afirma sua obrigatoriedade, define como local de realização as EEB, lembrando a corresponsabilidade entre os sistemas de ensino, bem como estabelece que o Estágio deva advir desde o $1^{\circ}$ ano do curso e que ambas as instituiçóes precisam participar do processo de avaliação do estagiário.

Por sua vez, a resolução CNE/CP 2/2002 estabelece a duração e a carga horária dos Cursos de Licenciatura Plena, de formação de professores da Educação Básica em nível superior, mediante o cumprimento de, no mínimo, 2.800 (duas mil e oitocentas) horas distribuídas entre teoria e prática. 
A partir da referida resolução, estabeleceu-se o aumento considerável na carga horária destinada à Prática como Componente Curricular e ao Estágio Curricular Supervisionado, ambos constituídos de carga horária de 400 (quatrocentas) horas, visando superar a separação entre teoria e prática e a desarticulação entre Universidade e Escola. Dessa maneira, os licenciandos anteciparão sua inserçâo na escola, seu contato com a realidade escolar e, sobretudo, com seu futuro campo de trabalho.

Verifica-se também, no parágrafo único, que os alunos que já estão exercendo atividades docentes poderão reduzir pela metade a carga horária exigida para o Estágio Curricular Supervisionado.

Nesse sentido, com base nas exigências previstas pela legislação atual, as IES devem, juntamente com as EEB, buscar subsídios para melhorias no processo de formaçáo inicial de professores, tanto na organização quanto no desenvolvimento do Estágio Curricular, proporcionando aos estagiários a oportunidade de inserção no campo profissional, sobretudo de fazer a relação entre teoria e prática e identificar os problemas da realidade profissional no decorrer da sua formação inicial.

Há na literatura da área educacional diversos autores que têm considerado o Estágio Curricular de extrema importância no âmbito do processo de formaçáo inicial de professores, e parte integrante de qualquer processo desse tipo. Podemos citar, por exemplo, Lima (1995), Kulcsar (1991), Pontuschka (1991), entre outros.

O Estágio Curricular tem a função principal de colocar o futuro professor em contato com o seu campo de trabalho, levando-o a avaliar a sua pertinência e a adequação de sua escolha profissional, bem como os desafios que a prática apresenta, além de sua própria satisfação com essa escolha. Nesse sentido, "o estágio representa para o aluno uma oportunidade de verificar o acerto de sua escolha profissional, já que é o momento em que a situação ensino-aprendizagem se realiza em toda a sua plenitude" (Pontuschka, 1991, p. 136). Por isso, o estágio proporciona ao aluno estagiário uma experiência única, durante sua formação inicial, sobre como exercer sua futura profissão em situaçóes reais de ensino.

Diante da conjuntura mencionada sobre os Estágios Curriculares nos Cursos de Licenciatura, procuramos, a partir de um recorte não diretamente oficial, caracterizar as "visóes" dos alunos estagiários, de modo a estabelecer sugestôes, subsídios e parâmetros que contribuam para a organização e o desenvolvimento de seus Estágios Curriculares. 
Percurso metodológico: uma abordagem acerca do desenvolvimento de pesquisa

Para compreendermos o processo de organização e desenvolvimento dos Estágios Curriculares, definimos, como fonte de informaçóes, os sujeitos alunos estagiários e, como instrumentos para coletar as informaçôes, utilizamos os questionários de perguntas abertas e grupos de discussão.

Conforme a definição de Richardson (1999, p. 192-193), o questionário de perguntas abertas "caracteriza-se por perguntas ou afirmaçóes que levam o entrevistado a responder com frases ou oraçôes. $\mathrm{O}$ pesquisador não está interessado em antecipar as respostas, deseja uma maior elaboraçâo das opinióes do entrevistado".

O Grupo de Discussão (GD) que promovemos foi inspirado no Grupo Focal, que "é uma técnica de entrevista em grupo que busca coletar informaçôes dos sentimentos e opiniôes dos investigados, sobre determinada questáo" (Matos; Vieira, 2002, p. 63). Esse instrumento foi utilizado com os alunos estagiários dos Cursos de Licenciatura, objetivando obter mais detalhes nas informaçóes sobre a investigação já mencionada, bem como suprir a possível falta de informaçóes a partir das constataçôes preliminares obtidas no questionário final.

Nesta pesquisa, utilizou-se a integração entre análise qualitativa e quantitativa, pois ambas podem se complementar e, assim, possibilitar várias interpretaçōes durante a análise das informaçôes. De acordo com Lenoir (2006, p. 08), "colocam em evidência a complementaridade enriquecedora entre dois tipos de métodos, utilizados segundo combinaçóes sequenciais ou em paralelo".

Para desenvolvermos esse estudo, inicialmente, elaboramos os questionários de perguntas abertas, que foram entregues aos alunos estagiários dos Cursos de Licenciatura da UFSM, em duas modalidades: questionário inicial e questionário final. E em dois momentos: fase inicial e fase final de Estágio Curricular.

No $1^{\circ}$ semestre de 2006, foram entregues cento e trinta e nove (139) questionários para alunos em fase inicial de Estágio Curricular e recolhidos noventa e dois (92). Também foram entregues cinquenta e sete (57) questionários àqueles em fase final de estágio e recolhidos quarenta e um (41). 
No $2^{\circ}$ semestre de 2006, foram entregues cento e trinta e um (131) questionários para estagiários em fase inicial e recolhidos apenas sessenta e seis (66). Também foram entregues cento e trinta e um (131) questionários aos alunos em fase final de estágios e recolhidos apenas trinta e um (31).

No $1^{\circ}$ semestre de 2007, foram distribuídos trezentos e quarenta e seis (346) questionários aos alunos estagiários em fase inicial de estágio e recolhidos apenas trinta e um (31).

Devido ao baixo retorno do questionário inicial, ainda, durante o $1^{\circ}$ semestre de 2007 , decidimos organizar e realizar os grupos de discussão. Num primeiro momento, elaboramos um roteiro constituído de dez (10) questôes, contemplando, entre elas, partes do questionário inicial e partes do questionário final. Também elaboramos um Termo de Concordância para que fossem autorizadas a gravação e a filmagem da sessão, para a utilização das informaçôes no desenvolvimento desta pesquisa.

Desse modo, foram realizadas dezesseis (16) sessóes, nas quais contamos apenas com a participação de cento e cinquenta e oito (158) alunos estagiários inseridos nos cursos investigados. Vale ressaltar que a participação era voluntária, então, novamente, não foi possível contar com a colaboração de um grande número de alunos estagiários.

Para a avaliação das informaçóes obtidas nos instrumentos utilizados, nos estudos realizados por Bardin (1977) encontramos notável relevância sobre o uso da análise de conteúdo e seguimos algumas orientaçóes para nortear nossa pesquisa. Entendemos que a análise de conteúdo é mais que uma leitura ipsis litteris de qualquer enunciado; ela se caracteriza por uma análise do trabalho, visando à compreensão crítica do significado das comunicaçóes.

Para a organização e a análise das informações obtidas nos questionários, primeiramente, as respostas foram digitadas na íntegra. Logo após, fizemos a leitura das respostas, tantas vezes quantas foram necessárias, para extrair a(s) ideia(s) central(is) expressa(s) na resposta. Após a localizaçáo dessa(s) ideia(s) central(is), agrupamos aquelas que faziam referência a uma mesma indicação. Por fim, fizemos as constataçóes apresentando a quantidade de frequências nas respostas e realizamos a análise das informações obtidas.

Para organizar as informações nas dezesseis (16) sessões de GD realizadas junto aos alunos estagiários, inicialmente, as entrevistas foram 
transcritas ipsis litteris e enviadas por correio eletrônico aos participantes das sessóes. Após a autorização dos depoentes para a utilização das informaçóes obtidas, as entrevistas foram lidas e relidas tantas vezes quanto necessárias para identificar a(s) ideia(s) central(is). Após a localização dessa(s), tabulamo-la(s) de acordo com as categorias definidas a priori, e realizamos a análise das informaçóes conseguidas.

\section{A formação inicial de acordo com os alunos estagiários: constataçóes e resultados}

Após a leitura e análise dos questionários e dos relatos obtidos junto aos alunos estagiários inseridos nos 13 Cursos de Licenciatura investigados, apresentamos as informaçóes obtidas no $1^{\circ}$ e $2^{\circ}$ semestres do ano de 2006 e no $1^{\circ}$ semestre do ano de 2007.

Constatamos, a respeito do relacionamento dos alunos estagiários com os professores orientadores durante o desenvolvimento de Estágios Curriculares, que quase todos consideraram como aspectos positivos a boa orientação recebida e, como aspectos negativos, a ausência do professor orientador na escola para assistir as aulas e a falta de tempo para as orientaçôes individuais. Houve exceção de alguns estagiários inseridos nos Cursos de Letras/Inglês, Artes Visuais e Educação Física, que não tiveram nenhum aspecto negativo a declarar.

Com relação à maneira como os alunos estagiários foram orientados para conseguir sua vaga na escola para realizar seus Estágios Curriculares nos Cursos investigados, noventa (90) indicaçôes afirmaram que foram orientadas pelo professor orientador e trinta e cinco (35) indicaçóes, referentes aos professores orientadores dos cursos de Matemática, Letras/ Português, Física, Ciências Biológicas, Filosofia, Letras/Inglês, Química e Educação Física, declararam que não receberam nenhuma orientação do professor orientador para conseguir sua vaga na escola para a realização do Estágio Curricular.

Percebemos que foi quase unânime a boa receptividade e o bom relacionamento entre os alunos estagiários e a escola. Com exceção de dez indicaçōes (10) entre os cursos de Letras/Espanhol, Física, Filosofia, Artes Visuais, Ciências Biológicas, Educação Física e Química, que alegaram que sentiram falta de receptividade por parte da escola. 
Em relação à questão da receptividade, esta foi fruto do passado dos alunos egressos dos cursos de Licenciatura pelas escolas, conforme nos contou o aluno estagiário,

Eu levei um sermão de meia hora da coordenadora no primeiro dia que eu cheguei, porque num outro ano um estagiário, um aluno de Biologia tinha sumido do Conselho de Classe da escola. Então, eu levei um sermão de meia hora frente ao aluno. (GD-CB-O1)

Nesse sentido, percebemos que a forma como as escolas receberam os alunos estagiários está relacionada ao fato de como os estagiários anteriores se comportaram na escola e, ainda, à origem da IES à qual pertencem. Diante desse relato, entendemos que a escola onde aconteceu o fato mencionado teve receio de receber novamente estagiários. Porém, não concordamos com essa atitude da escola, por dois motivos: primeiramente, por fazer o estagiário ouvir um "sermão" por algo que ele não havia cometido e, em segundo lugar, porque a conversa náo foi apenas entre as pessoas interessadas no momento, ou seja, diretora, coordenadora pedagógica e aluno estagiário, mas diante dos alunos da escola.

Quanto ao relacionamento com as escolas, houve quatro (04) indicaçôes, nos cursos de Artes Visuais, Letras/Espanhol, Física e Filosofia, que afirmaram que a relação foi "quase harmoniosa, hostil e com desconfiança".

Em relação às colocaçóes feitas pelos alunos estagiários, a respeito da participação do professor regente, percebemos que estes não participaram com os estagiários "na elaboração de seus planejamentos", quando a escola segue o Programa de Ingresso ao Ensino Superior (Peies). "Na condução das aulas", constatamos que há um consenso entre os alunos estagiários e os professores regentes quanto à ausência dessa participação. "No enfrentamento dos desafios ou dificuldades", percebemos que os estagiários necessitam também contar com o apoio da direçâo da escola para que os alunos colaborem com o trabalho deles. "Na avaliação do seu estágio curricular", obtivemos treze (13) indicaçóes no curso de História que alegaram que os professores regentes emitiram um parecer referente ao desempenho do aluno estagiário, e, no curso de Educação Física, duas (02) indicaçôes alegaram que os professores regentes preencheram um questionário a respeito do desempenho dos seus estagiários.

No que diz respeito à maneira como os alunos estagiários foram acompanhados pelas escolas para a realização dos Estágios Curriculares, po- 
demos sintetizar como: conversas com a diretora, coordenadora pedagógica, supervisora, professor regente, por reuniōes, pela entrega dos Planos de Aula, pelas aulas ministradas e pelo atendimento realizado.

Evidenciamos, também, vinte e uma (21) indicaçōes nos cursos de Letras/Espanhol, Física, Filosofia, Artes Visuais, Educação Física, História, Química e Música que afirmaram que a escola não acompanhou os estagiários no decorrer da realizaçấo do estágio. Ainda, obtivemos quatro (04) indicaçôes, sendo uma (01) no curso de Artes Visuais e três (03) no curso de Educaçấo Física, declarando que o acompanhamento da escola foi quase inexistente.

Os resultados mostram, pois, um dado preocupante quanto à falta de acompanhamento da escola aos alunos estagiários durante a realizaçáo do Estágio Curricular. Portanto, consideramos de extrema importância o trabalho conjunto entre as agências formadoras na medida em que os professores das escolas são educadores que possuem experiência, construída no decorrer de sua atuação no contexto educativo. Por isso, a participação desses professores no processo formativo é essencial, porque eles conhecem a realidade da escola, assim como a dos alunos que a frequentam e, dessa maneira, podem contribuir para preparar melhor o seu futuro colega de profissão. De acordo com Putnam e Borko (2000, p. 223):

Los profesores de formación del profesorado deberían tratar a los maestros de la misma manera como esperan que los maestros traten a sus alumnos. [...] Es más, los profesores de formación del profesorado deberían introducir a los maestros en las actividades y las formas de interacción que a su vez esperan de los estudiantes.

Nesse sentido, somos levados a questionar: Por que a escola quase não acompanha o processo de formaçáo inicial dos futuros profissionais que nela atuarão? Por que não ocorre a corresponsabilidade entre os sistemas de ensino previstos nas normativas legais? Entendemos que, com mudanças, poderia ocorrer um trabalho mais sólido e consistente, possibilitando amenizar as lacunas na formação inicial do futuro professor.

Nos cursos de Licenciatura, dos cento e cinquenta e quatro (154) respondentes, obtivemos cento e cinquenta e uma (151) indicaçóes para as disciplinas de "Conhecimento pedagógico de conteúdo", cento e nove (109) indicaçóes para as disciplinas de "Conhecimento de conteúdo específico" e somente quarenta (40) indicaçóes para as disciplinas de "Conhecimento pedagógico geral". 
Ainda, obtivemos oito (08) indicaçóes, duas (02) no curso de Filosofia, uma (01) do curso de Ciências Biológicas, uma (01) do curso de Educação Física, uma (01) do curso de Matemática, duas (02) do curso de Artes Visuais e uma (01) para o curso de História, alegando que todas as disciplinas cursadas contribuíram para a realização do Estágio Curricular.

Perante os resultados, evidenciamos que os cursos de Licenciatura estão proporcionando aos alunos estagiários, a partir das disciplinas citadas, uma base para a formação inicial. Na conclusão de Lima (2002, p. 07), “o Estágio componente curricular configura-se como atividade fundamental na Didática. A abrangência da Didática e do Estágio está além de seus limites e abarca todas as disciplinas de forma articuladora e interdisciplinar".

Constatamos que o Estágio Curricular, para quase todos $(97,0 \%)$ os alunos estagiários, foi considerado como um momento importante para a formação do futuro professor, um período de aprendizagens que proporciona o contato com as dificuldades da prática pedagógica e permite vivenciar a realidade escolar. No entanto, para alguns (3,0\%) estagiários inseridos nos cursos de Geografia, Educação Física e Matemática, o Estágio Curricular foi considerado uma fase de experiências negativas, em função, principalmente, da indisciplina dos alunos da Escola de Educação Básica (EEB).

Percebemos que o motivo que levou os alunos estagiários à decepção de serem professores no futuro foi, principalmente, a indisciplina dos alunos da $\mathrm{EBB}$, situação esta para a qual não foram preparados, fato que ajudou a formar uma ideia negativa da realidade escolar no momento atual. Oliveira e Lampert (2006, p. 05) propóem que “o estágio seja um momento de superação de obstáculo, de diálogo e de liçóes em seus fundamentos teóricos e práticos. Que cada estagiário encontre sua identidade como professor”. Portanto, nas sugestóes das autoras, o estágio é também o momento de aprender a superar as dificuldades que fazem parte da realidade escolar. Trata-se de fazer uma inter-relação mais efetiva entre a teoria e a prática, visando testar os conhecimentos adquiridos ao longo do curso.

Sabemos que há um consenso na literatura ao considerar o Estágio Curricular de extrema importância para a formação inicial de professores, tendo como função realizar a interação universidade-escola, promovendo a relação teoria-prática, de forma a, assim, proporcionar uma experiência única aos alunos estagiários no modo como exercer sua profissão em situações reais de trabalho. De acordo com Kulcsar (1991, p. 65): 
O estágio supervisionado deve ser considerado um instrumento fundamental no processo de formação do professor. Poderá auxiliar o aluno a compreender e enfrentar o mundo do trabalho e contribuir para a formação de sua consciência política e social, unindo a teoria à prática.

Na nossa concepção, o Estágio Curricular é considerado como espaço de formação, aprendizagem, produção de conhecimentos, pesquisa, é o início da construção da identidade profissional e, sobretudo, o encontro entre experiência e conhecimento.

Percebemos, com base em nossa pesquisa, que o Estágio Curricular configura-se como espaço de formação que tem a função de colocar o futuro professor em contato com o seu campo de trabalho, proporcionando ao aluno estagiário uma experiência única, muito rica, de saber como exercer sua futura profissão em situaçóes reais de ensino.

\section{Consideraçóes finais}

O estudo realizado acerca do processo de organização e desenvolvimento de Estágios Curriculares na UFSM mostra, a partir das informaçōes obtidas junto aos alunos estagiários, os problemas existentes na Formação Inicial em Cursos de Licenciatura.

Quanto aos aspectos que caracterizam o relacionamento entre aluno estagiário e professor orientador, podemos afirmar que há um bom empenho por parte destes em atender os orientandos em qualquer momento em que haja necessidade de auxílio para melhorias na qualidade das aulas. Constatamos que a maioria $(58,33 \%)$ dos professores orientadores costuma participar ativamente da inserção dos alunos estagiários na escola, concedendo cartas de apresentação, fazendo contato e apresentando listas de escolas conveniadas com a UFSM. Esse primeiro contato, no entanto, é feito exclusivamente pelo aluno estagiário, que procura a escola de acordo com o seu interesse e com a possibilidade de realização do Estágio Curricular.

No que tange à aceitação e à recepção dos alunos estagiários na escola, podemos afirmar que a maioria deles foi recebida por alguma pessoa que faz parte da equipe diretiva ou pelo professor regente de turma. E essa boa receptividade se deve ao fato de as escolas já possuírem um conhecimento 
sobre o trabalho que os estagiários, referentes ao mesmo curso, assim como do mesmo orientador e da mesma IES, costumam realizar nas escolas.

No entanto, nossa investigação mostrou que o motivo que levou as escolas a receberem os alunos estagiários com apatia, ou simplesmente não recebê-los, foi fruto das experiências negativas com os estagiários egressos dos cursos de Licenciatura em anos anteriores.

Percebemos também que não há uma participação constante dos professores regentes de turma junto aos alunos estagiários durante a realização do Estágio Curricular. Dessa maneira, podemos afirmar que a responsabilidade pela formação inicial do futuro professor está mais centrada na IES. Isso, tendo em vista que as $\mathrm{EEB}$ parecem ainda não conceber o Estágio Curricular como uma forma de trabalho coletivo entre as agências formadoras, conforme está previsto na Resolução CNE/CP 1/2002, em seu artigo 13, parágrafo 3, quando faz referência à "colaboração entre os sistemas de ensino".

Consideramos de extrema importância o trabalho conjunto entre as agências formadoras, na medida em que os professores das escolas são educadores que possuem experiência, a qual foi construída no decorrer da sua atuação no contexto educativo. Por isso, a participação desses professores no processo formativo é essencial, porque eles conhecem a realidade da escola, assim como a dos alunos que a frequentam e, dessa maneira, podem contribuir para preparar melhor o seu futuro colega de profissão.

Mediante a análise sobre a forma como as EEB realizaram o acompanhamento dos alunos estagiários, percebemos que estas se centram em diálogos com algumas das pessoas que fazem parte da equipe diretiva da escola, por meio de reunióes realizadas semanalmente ou quinzenalmente, ou fica a cargo do professor regente. Além disso, algumas escolas não acompanham o aluno estagiário, somente verificam o livro de ponto para se certificarem do cumprimento das aulas assumidas por aquele.

Nesse sentido, consideramos preocupante a falta de acompanhamento das escolas quanto aos alunos estagiários nessa etapa inicial, considerada fundamental para a formação dos futuros professores. Porém, tal atitude das escolas nos levou a perceber que elas ainda não conceberam o Estágio Curricular como um trabalho coletivo, que necessita imensamente que haja a interação entre a universidade e a escola para, assim, formar docentes aptos a praticar um ensino significativo. 
A análise dos cursos investigados mostrou que as disciplinas que mais contribuíram para a realização dos Estágios Curriculares foram aquelas relacionadas ao conhecimento conceitual da matéria de ensino. Contudo, nossa investigação apresentou alguns casos em que o Estágio Curricular foi considerado como uma fase de experiências negativas, em razão, principalmente, da indisciplina dos alunos da EEB, conforme já mencionado. Trata-se de uma situação para a qual os estagiários não foram preparados, o que ajudou a formar uma ideia negativa a respeito da realidade escolar contemporânea. Em seus registros e depoimentos, não foi possível perceber aprendizagem específica de vida com a realização de seus estágios.

Em suma, concluímos que, para haver melhorias na formação inicial, não basta a IES adaptar-se ao cumprimento de aspectos primários das normativas legais (tais como as 400 horas de atividades de Estágio Curricular). Faz-se necessário buscar formas de interação que estimulem um comprometimento intenso dos formadores de professores que atuam nas Escolas de Educação Básica (EEB) e nas Instituições de Ensino Superior (IES), de forma a proporcionarem acompanhamento e auxílio, visando superar algumas dificuldades enfrentadas pelos estagiários, como a falta de orientaçóes individuais, acompanhamento e auxílio no desenvolvimento de seus estágios.

\section{Referências}

AGOSTINI, S. A Organização e o Desenvolvimento de Estágios Curriculares em Cursos de Licenciatura da UFSM: Envolvimentos de Estagiários e Orientadores. 2008. Dissertação (Mestrado em Educação) - Universidade Federal de Santa Maria, Santa Maria/RS, 2008. Disponível em: <http://www.dominiopublico.gov.br/pesquisa/DetalheObraForm.do?select_action=\&co_ obra $=110837>$. Acesso em: 03 fev. 2010.

BARDIN, L. Análise de Conteúdo. Lisboa: Edições 70, 1977.

BRASIL, Ministério da Educação, Conselho Nacional de Educação. Resolução CNE/CP 01, de 18 de fevereiro de 2002 - Institui Diretrizes Curriculares Nacionais para a Formação de Professores da Educação Básica, em nível superior, cursos de Licenciatura, de graduação plena. Brasília: Diário Oficial da União, 09 abr. 2002 1, p. 31, 2002a. Disponível em: <http://portal.mec.gov.br/cne/arquivos/pdf/CP022002.pdf>. Acesso em: 22 fev. 2007. 
. Conselho Nacional de Educação. Resoluçáo CNE/CP 02, de 19 de fevereiro de 2002 - Institui a duração e a carga horária dos cursos de Licenciatura, de graduação plena, de formação de professores da Educação Básica em nível superior. Brasília: Diário Oficial da União, 04 mar. 2002, Seção 1. p. 9, 2002b. Disponível em:<htt://portal.mec.gov.Br/cne/arquivos/pdf/ rcp01_02.pdf>. Acesso em: 22 fev. 2007.

. Lei de Diretrizes e Bases da Educação Nacional no 9.394 de 20 de dezembro de 1996 - Estabelece as Diretrizes e Bases da Educação Nacional. Brasília: MEC, 1996. Disponível em: <htt://www.planalto.gov.Br>. Acesso em: 17 abr. 2007.

KULCSAR, R. O estágio supervisionado como atividade integradora. In: PICONEZ, S. B. (Coord.). A prática de ensino e o estágio supervisionado. São Paulo: Papirus, 1991.

LENOIR, Y. Pesquisar e formar: repensar o lugar e a função da prática de ensino. Educação e Sociedade. Campinas, v. 27, n. 97, p. 1299-1325, 2006. Disponível em: <http://www.scielo.br/scielo.php?script=sci_arttex\&pid=S0 $101733302006000400011 \&$ Ing=pt\&nrm=isso $>$. Acesso em: 20 abr. 2008.

LIMA, M. S. L. Práticas de Estágio Supervisionado em Formação Continuada. In: ROSA, D. E. G.; SOUZA, V. C. de; FELDMAN, D. Didática e Práticas de Ensino: interfaces com diferentes saberes e lugares formativos. Rio de Janeiro: DP\&A, 2002.

MATOS, K. S. L; VIEIRA, S. L. Pesquisa Educacional: o prazer de conhecer. 2. ed. Fortaleza: Edições Demócrito Rocha, 2002.

OLIVEIRA, M. O. de; LAMPERT, J. O Estágio Curricular como Campo de Conhecimento e suas Especificidades no Ensino de Artes Visuais. In: Revista Digital Art\&, ano IV, n. 6, out. 2006. Disponível em: <http:// www.revista.art.br/site-numero-06/apresentacao.htm>. Acesso em: 16 abr. 2009.

PONTUSCHKA, N. N. A Formação Inicial do Professor de Geografia. In: PICONEZ, S. B. (Coord.). A prática de ensino e o estágio supervisionado. São Paulo: Papirus, 1991. 
PUTNAM, R. T.; BORKO, H. El Aprendizaje del Profesor: implicaciones de las nuevas perspectivas de la cognición. In: BIDDLE, B. J.; GOOD, T. L. e GOODSON, I. F. (Orgs.). La Enseñanza y los Profesores, I: La profesión de enseñar. Barcelona: Editorial Paidós, 2000. p. 219-309.

RICHARDSON, R. J. Pesquisa Social: métodos e técnicas. 3. ed. São Paulo: Atlas, 1999.

Recebido em: 09 maio 2010

Aceito em: 20 jun. 2010 